\title{
Clinical outcomes of endoscopic resection for superficial non-ampullary duodenal tumors
}

\section{다)(1) $\odot$}

\author{
Authors \\ Yoshifuku $^{1}$, Koji Arihiro ${ }^{3}$, Shinji Tanaka², Kazuaki Chayama ${ }^{1}$ \\ Institutions \\ 1 Department of Gastroenterology and Metabolism, \\ Hiroshima University Hospital, Hiroshima, Japan \\ 2 Department of Endoscopy, Hiroshima University \\ Hospital, Hiroshima, Japan \\ 3 Department of Anatomical Pathology, Hiroshima \\ University Hospital, Hiroshima, Japan
}

Kazutaka Kuroki ${ }^{1}$, Yoji Sanomura ${ }^{2}$, Shiro Oka ${ }^{1}$, Naoki Yorita', Mio Kurihara', Takeshi Mizumoto ${ }^{1}$, Yoshikazu

submitted 5.6 .2018

accepted after revision 5.2.2019

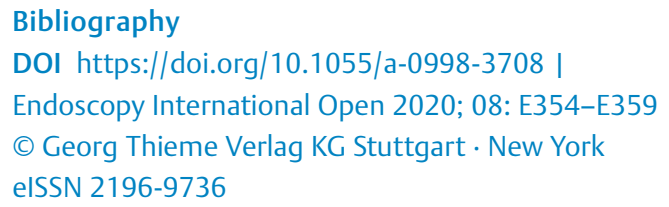

Corresponding author

Yoji Sanomura, MD, PhD, Department of Endoscopy, Hiroshima University Hospital, 1-2-3 Kasumi, Minami-ku, Hiroshima 734-8551, Japan

Fax: +81-82-257-5939

y-sanomura@hiroshima-u.ac.jp

\section{ABSTRACT}

Background and study aims Because superficial non-ampullary duodenal epithelial tumors (SNADETs) are relatively rare, studies evaluating the outcomes of endoscopic resec- tion (ER) for SNADETs are limited. Therefore, this study aimed to evaluate the clinical validity of ER for SNADETs.

Patients and methods The study participants included 163 consecutive patients (108 men; mean age, $61.5 \pm 11.3$ years) with 171 SNADETs, excluding patients with familial adenomatous polyposis resected by ER, at Hiroshima University Hospital between May 2005 and September 2016. Clinicopathological features and the outcomes of ER for 171 cases were retrospectively analyzed. Additionally, the prognosis of 135 patients with more than 12 months' follow-up was analyzed.

Results Mean diameter of SNADETs was $10.7 \pm 7.2 \mathrm{~mm}$. Most of the SNADET cases were classified as category 3 $(71 \%, 121 / 171)$, but some were category 5 (2\%,3/171). En bloc resection rates were $93 \%$ (146/157), 100\% (7/7), and $86 \%(6 / 7)$ in endoscopic mucosal resection (EMR), polypectomy, and in endoscopic submucosal dissection (ESD) cases, respectively. Complete resection rates were $90 \%$ (141/157), $100 \%(7 / 7)$, and $71 \%$ (5/7) in EMR, polypectomy, and ESD cases, respectively. Emergency surgery was performed in two patients with intraoperative perforation and in two with delayed perforation without artificial ulcer bed closure after ER. Since endoscopic closure of ulcer by clipping was performed, delayed perforation has not occurred. Local recurrence occurred in $1.2 \%$, but no metastasis to lymph nodes or other organs occurred after ER. No patient died of primary SNADETs.

Conclusion Our data supported the clinical validity of ER for SNADETs. However, delayed perforation should be given much attention.

\section{Introduction}

Superficial non-ampullary duodenal epithelial tumors (SNADETs) are defined as sporadic adenoma and adenocarcinoma that are confined to the mucosa or submucosa that do not arise from the ampulla of Vater [1]. Because of the rarity of SNADETs [2], their etiology, prevalence, and risk factors remain unknown. It was reported that SNADETs were detected using esophagogastroduodenoscopy (EGD) in adult patients at a rate of $0.1 \%$ to $0.3 \%$ [3]. Some retrospective studies reported that the prevalence rate of SNADETs in patients referred for EGD is $0.3 \%$ to $1.5 \%$ [4]. Regarding the histopathological type of SNADETs, duodenal polyps are found in $1.5 \%$ to $4.6 \%$ of routine EGD. The incidence rate for adenocarcinoma of the small intestine is 6.8 per million [5], and about $47 \%$ to $58 \%$ were duodenal adenocarcinomas in the small intestine [6].

Almost all SNADETs are detected coincidentally by EGD, and almost all symptomatic patients with gastrointestinal bleeding were at an advanced stage of duodenal adenocarcinoma [3, 7].

Malignant transformation is another problem of SNADETs. Duodenal adenoma was reported to be a precancerous lesion with a relatively high rate of canceration [2]. Some reports sug- 
gested that there were two carcinogenesis pathways of duodenal carcinoma: the adenoma-carcinoma sequence and the development of de novo cancer [1,7-9]. The prognosis of duodenal adenocarcinoma has the lowest 5-year survival rate of all small intestinal carcinomas, being less than $30 \%$ [6]. Because, as mentioned previously, several SNADETs are asymptomatic, duodenal carcinoma commonly is detected at an advanced stage, and its prognosis is dismal [6]. Therefore, resection of SNADETs detected using EGD may be reasonable before carcinogenesis by the adenoma-carcinoma sequence. However, owing to the low prevalence of SNADETS, information concerning the diagnosis and treatment strategy for them is very limited.

Thus, this study aimed to investigate outcomes of endoscopic resection (ER) in patients with SNADETs including their prognosis to confirm the validity of ER for SNADETs.

\section{Patients and methods}

\section{Patients}

A retrospective study was performed with 225 consecutive non-ampullary duodenal tumors in 209 patients detected at Hiroshima University Hospital between May 2005 and September 2016. Of the 209 patients, 19 patients with non-epithelial tumor, 18 patients diagnosed with familial adenomatous polyposis (FAP), and nine patients who were treated by except with ER (4 patients treated by argon plasma coagulation (APC), hot biopsy, and/or heat probe, 5 patients treated by surgical resection) were excluded ( $\triangleright$ Fig. 1).

First, clinicopathological features and outcomes of ER (en bloc resection, complete resection, and complications) were analyzed in 163 patients with 171 SNADETs. Second, the prognosis of 136 patients whose follow-up period was more than 12 months was analyzed. Informed consent for ER was obtained from all patients, and this study was conducted with approval from the Institutional Review Board of Hiroshima University.

\section{Indications and procedures for ER}

We basically treated the SNADETs diagnosed by endoscopic observation or biopsy. As ER for SNADETs, we decided that the therapeutic procedure was based on lesion size and shape. EMR was selected, but for lesions $\geq 25 \mathrm{~mm}$, piecemeal EMR was the method used to resect them until July 2010, and since then, endoscopic submucosal dissection (ESD) was performed. Indications for surgery on SNADETs were the following: 1. Tumor too large to achieve en bloc resection, specifically more than $30 \mathrm{~mm}$; 2. Endoscopic manipulation too poor to achieve en bloc resection; and 3. SNADETs spread over ampulla of Vater.

Polypectomy was performed by six endoscopists using a single-channel endoscope (H260Z; Olympus Optical Co., Ltd., Tokyo, Japan, or EG450DG5; Fujifilm Medical, Tokyo, Japan). EMR was performed by 10 endoscopists using a single-channel endoscope (H260, H260Z or Q260); Olympus Optical Co., Ltd., Tokyo, Japan, or EG-450RD5 or EG-450D5; Fujifilm Medical, Tokyo, Japan). Polypectomy and EMR were performed using two kinds of snares as appropriate to the size or lesion in EMR (SD210L-10 or SD-230U-20; Olympus Optical Co., Ltd., Tokyo, Japan). In EMR, electrosurgical current to cut the SNADETs was
209 consecutive patients with 225 non-ampullary duodenal tumor were detected by endoscopic screening until September 2016

\section{Excluded: \\ 19 patients with non-epithelial tumor 18 patients diagnosed FAP \\ 4 patients treated by APC, hot biopsy, heat probe \\ 5 patients treated by surgical operation}

163 consecutive patients with 171 SNADETs were treated with ER until September 2016, and were analyzed of clinicopathological feature and treatment outcome

27 patients whose follow-up period less than 12 months were excluded

135 patients with 137 SNADETs were included in the analysis of prognosis

FAP: familial adenomatous polyposis, APC: Argon plasma coagulation, SNADETs: superficial non-ampullary duodenal epithelial tumors

Fig. 1 Flowchart of patients and tumors included in the study.

applied using an electrosurgical generator (ICC-200, EndoCut Q mode, effect 2, Cut-duration 3, Cut-interval 3, Erbe Co., Tubingen, Germany) and to coagulate the ulcer after EMR was applied same electrosurgical generator (40W, Erbe ICC-200). After injecting $10 \%$ glycerin solution and/or $4 \%$ sodium hyaluronate into the submucosa, lesions were resected by snare. ESD was performed by two endoscopists using a single-channel endoscope (H260 or H260Z, Q260]; Olympus Optical Co., Ltd., Tokyo, Japan, or EG-450RD5; Fujifilm Medical, Tokyo, Japan) or a two-channel scope (GIF-2TQ260 M, Olympus, or EG-450D5; Fujifilm Medical). After injecting $10 \%$ glycerin solution and/or $4 \%$ sodium hyaluronate into the submucosa, the circumferential mucosa was cut around the lesion using an SB Knife Jr (Sumitomo Bakelite Co., Ltd., Tokyo, Japan) or DualKnife (Olympus Optical Co., Ltd., Tokyo, Japan). If residual lesions were found just after ER for SNADETs, we also treated them using APC or heat probe. At the end of the procedure, all exposed vessels on the artificial ulcer were coagulated using hemostatic forceps (FD-410LR; Olympus or HDB2418 W-W; Pentax, Tokyo, Japan). Since March 2010, endoscopic closure of ulcer is always performed after ER by clipping or detachable snaring to prevent delayed perforation. Starting on the day of ER, proton pump inhibitor or potassium competitive acid blocker was administered. Second-look endoscopy was consistently performed on the day after ER. After hemostasis was confirmed, the patient was permitted to eat a light meal in the evening or the next day. 


\section{Histopathological examination and curability after ER}

Histopathological examination was based on the Vienna classification [10]. The resected specimens were sliced at 2-mm intervals and the sections were examined under hematoxylin and eosin staining for detailed analysis. En bloc resection was defined as resection in a single piece. Complete resection was defined as en bloc resection of a tumor that was shown to be cancer-free and/ or adenoma cells at the horizontal and vertical cut ends. Curative resection was defined as the following: adenoma, intramucosal carcinoma (category 3 or 4 tumors according to the Vienna classification), en bloc removal, negative horizontal margin (HMO), negative vertical margin (VMO), and no lymphovascular infiltration.

\section{Follow-up after ER}

The interval period of follow-up EGD for local recurrence was generally scheduled according to curability. In cases of curative resection, follow-up examination was performed 6 to 12 months after the procedure and once every 12 months thereafter; in cases of incomplete resection, follow-up examination was performed 3 to 6 months after the procedure and, if there was no recurrence, then every 12 months thereafter. All patients who underwent ER for SNADETs before September 2016 were reviewed under an Institutional Review Board (IRB) (approved protocol, IRB No. E-195-1 at Hiroshima University).

\section{Statistical analysis}

Statistical differences were evaluated using Wilcoxon or Kruskal-Wallis test, and a value of $P<0.05$ was considered statistically significant.

\section{Results}

\section{Patients and lesion characteristics}

A total of 171 SNADETs in 163 consecutive patients were included in this study (108 men, 55 women; mean age, 61.5 \pm 11.3) ( Table 1). SNADETs were located in the following locations: 38 (22\%), 126 (74\%), and 7 (4\%) in the first, second, and third portions, respectively, of the duodenum. Mean diameter of SNADETs was $10.7 \pm 7.2 \mathrm{~mm}$; the macroscopic types were the following: 43 (25\%), 92 (54\%), 11 (6\%), and 25 (15\%) were types 0-I, 0-Ila, 0-Ila + IIc, and 0-Ilc, respectively. Colors of SNADETs were described as follows: 52 (30\%), 49 (29\%), and 68 (41\%) were reddish, whitish, and isochromatic, respectively. Ninety-six SNADETs had a milk-white mucosa (66\%) [11].

In pathological diagnosis, 121 (71\%), 47 (27\%), and $3(2 \%)$ SNADETs were classified as category 3 , category 4 , and category 5 , respectively.

\section{Outcomes of ER}

- Table 2 shows outcomes of ER for SNADETs. In this study, 157 (92\%), 7 (4\%), and 7 (4\%) SNADETs were treated by EMR, polypectomy, and ESD, respectively.

Rates of en bloc resection were achieved successfully in $93 \%$ (152/157), $100 \%$ (7/7), and $86 \%$ (6/7) by EMR, polypectomy,
- Table 1 Clinicopathological characteristics in patients with SNADETs who underwent ER.

Sex

\begin{tabular}{l|r}
\hline - Male & $108(66)$ \\
\hline Female & $55(34)$ \\
\hline
\end{tabular}

Location in duodenum

- First part $38(22$

- Second part $126(74)$

- Third part $7(4)$

\begin{tabular}{l|l} 
Tumor diameter, $\mathrm{mm}$ (range) & $10.7 \pm 7.2(3-35)$
\end{tabular}

$\begin{array}{ll}\text { Age, mean } \pm S D \text {, years } & 61.5 \pm 11.3\end{array}$

Macroscopic type

$\begin{array}{lll}0-1 & 43(25)\end{array}$

0-lla $92(54)$

$0-11 \mathrm{a}+\mathrm{Ilc} \quad 11(6)$

0-Ilc $25(15)$

Color

- Reddish $52(30)$

- whitish 49 (29)

- Isochromatic $70(41)$

Milk-white mucosa

- Present $96(66)$

- Absent 49 (34)

Treatment

- EMR $157(92)$

- Polypectomy 7 (4)

- ESD

$7(4)$

Histologic type and depth of invasion

- Category 3 121(71)

- Category $4 \quad 47$ (27)

- Category 5

SNADETs, superficial non-ampullary duodenal epithelial tumors (\%); SD, standard deviation; EMR, endoscopic mucosal resection; ESD; endoscopic submucosal dissection

and ESD, respectively. Rates of complete resection were $90 \%$ (141/157), $100 \%(7 / 7)$, and $71 \%$ (5/7) in EMR, polypectomy, and ESD cases, respectively. Reasons for incomplete resection were poor operability of endoscopy in all cases, and five were because of non-lifting after injection.

Complications occurred in 12 cases (7\%); postoperative bleeding (4 after EMR and 1 after polypectomy), intraoperative perforation (2 during EMR, 1 during ESD), and delayed perforation after EMR occurred in 5, 3, and 4 cases, respectively. Four cases underwent emergency surgery ( 2 cases, intraoperative 
Table 2 Outcome of ER for SNADETs.

\begin{tabular}{|c|c|c|c|c|c|c|c|c|c|c|c|}
\hline \multirow{3}{*}{$\begin{array}{l}\text { Factor } \\
\text { Tumor size (mm) }\end{array}$} & \multicolumn{11}{|c|}{ ER method } \\
\hline & \multicolumn{4}{|c|}{$\operatorname{EMR}(n=157)$} & \multicolumn{4}{|c|}{ Polypectomy $(n=7)$} & \multicolumn{3}{|c|}{$\operatorname{ESD}(n=7)$} \\
\hline & $\begin{array}{l}1-10 \\
n=116\end{array}$ & $\begin{array}{l}11-20 \\
n=37\end{array}$ & $\begin{array}{l}21- \\
n=4\end{array}$ & Total & $\begin{array}{l}1-10 \\
n=2\end{array}$ & $\begin{array}{l}11-20 \\
n=3\end{array}$ & $\begin{array}{l}21- \\
n=2\end{array}$ & Total & $\begin{array}{l}11-20 \\
n=2\end{array}$ & $\begin{array}{l}21- \\
n=5\end{array}$ & Total \\
\hline En bloc resection & $113(97)$ & $35(95)$ & $4(100)$ & $152(97)$ & $2(100)$ & $3(100)$ & $2(100)$ & $7(100)$ & $1(50)$ & $5(100)$ & $6(86)$ \\
\hline Complete resection & $103(89)$ & $34(92)$ & $4(100)$ & $141(90)$ & $2(100)$ & $3(100)$ & $2(100)$ & $7(100)$ & $1(50)$ & $4(80)$ & $5(71)$ \\
\hline $\begin{array}{l}\text { Postoperative bleed- } \\
\text { ing }\end{array}$ & $0(0)$ & $2(5)$ & $2(50)$ & $4(3)$ & $0(0)$ & $0(0)$ & $1(50)$ & $1(14)$ & $0(0)$ & $0(0)$ & $1(14)$ \\
\hline $\begin{array}{l}\text { Intraoperative per- } \\
\text { foration }\end{array}$ & $0(0)$ & $1(3)$ & $0(0)$ & $1(1)$ & $0(0)$ & $0(0)$ & $0(0)$ & $0(0)$ & $1(50)$ & $0(0)$ & $1(14)$ \\
\hline Delayed perforation & $0(0)$ & $2(5)$ & $2(50)$ & $4(3)$ & $0(0)$ & $0(0)$ & $0(0)$ & $0(0)$ & $0(0)$ & $0(0)$ & $0(0)$ \\
\hline Local recurrence & $2(2)$ & $0(0)$ & $0(0)$ & $2(1)$ & $0(0)$ & $0(0)$ & $0(0)$ & $0(0)$ & $0(0)$ & $0(0)$ & $0(0)$ \\
\hline
\end{tabular}

perforation; 2 cases, delayed perforation), but the other cases could be treated by conservative treatment. In all four cases that underwent emergency surgery, we achieved en bloc resection. Tumor in one case with intraoperative perforation was located in the first portion of the duodenum and tumors in the other three cases were located at the opposite side of the ampulla of Vater. Delayed perforation occurred in four cases. In all four cases, we achieved en bloc resection. Tumor in one case was located at post-ampulla of Vater and tumors in the other three cases were located at the opposite side of ampulla of Vater. Rates of postoperative bleeding were $0 \%(0 / 116), 5 \%$ $(2 / 37)$, and $50 \%(2 / 4)$ in the lesions $\leq 10 \mathrm{~mm}, 11$ to $20 \mathrm{~mm}$, and $\geq 21 \mathrm{~mm}$, respectively. No patient with postoperative bleeding was prescribed any antithrombotic or antiplatelet drugs. Rates of delayed perforation were $0 \%(0 / 116), 5 \%$ (2/37), and $50 \%(2 / 4)$ in lesion $\leq 10 \mathrm{~mm}, 11$ to $20 \mathrm{~mm}$, and $\geq 21 \mathrm{~mm}$. The rate of postoperative bleeding and delayed perforation was significantly higher in tumors $\geq 11 \mathrm{~mm}$ than in lesion $\leq 10 \mathrm{~mm}(P=0.003)$.

As for the prognosis, there were two local recurrences among the 135 patients who were followed for $>12$ months (mean follow-up period: $53.2 \pm 34.2$ months). In the two cases with local recurrence, we achieved en bloc resection. Those two tumors were located in pre-ampulla of Vater and were $\leq 10 \mathrm{~mm}$ and diagnosed as category 3 after EMR. The two cases were treated with EMR again and achieved complete resection. Two patients with a category 5 lesion underwent additional surgical resection with lymph node dissection, but neither patient had lymph node metastasis. One patient who did not undergo additional surgical resection for a category 5 lesion had no recurrence during follow-up. None of the patients died of primary SNADETs, resulting in a disease-specific survival rate of $100 \%$.

\section{Discussion}

Our data showed that ER for SNADETs achieved over $90 \%$ en bloc resection and complete resection rates; especially, en bloc resection rate showed good results irrespective of the tumor diameter. En bloc resection and complete resection rates were higher for EMR than for ESD in this study. In fact, we changed the method of ER for SNADETs from EMR to ESD during the operation when we determined that it was difficult to achieve en bloc resection with EMR. We resected seven lesions by ESD. Five of those lesions were $>30 \mathrm{~mm}$ and we determined that it was difficult to achieve en bloc resection with EMR and performed ESD. ESD was performed in one of seven lesions because the lesion was non-lifting sign-positive. One of seven lesions was located in the superior duodenal angle and thus it was difficult to put the snare on it. According to the clinicopathological characteristics of SNADETs in our data, most of the SNADETs were adenomas with a diameter $\leq 20 \mathrm{~mm}$. In addition, the prognosis of SNADETs was good because the rate of local recurrence was low and no patient died of the primary SNADETs. Therefore, our results suggested that ER for SNADETs was feasible, which can cure the condition. ER for SNADETs was done for the purpose of total excisional biopsy. Therefore, we basically performed ER for SNADETs when en bloc resection by ER was considered possible even if the tumor diameter was $\leq 5 \mathrm{~mm}$. We previously reported that magnifying narrow-band imaging endoscopy (ME-NBI) and pit pattern analyses have clinical usefulness to distinguish category 3 SNADETs from category 4 according to the Vienna classification [12]. However, differentiating category 4 from category 5 using ME-NBI is difficult in some cases $[11,12]$. It was reported that 0 -I or 0 -Ila + Ilc macroscopic types with a red color were usually endoscopic features of submucosal carcinoma [1]. It was reported that central dimpling or ulceration suggested the endoscopic features of submucosal carcinoma [13]. It was reported that mean diameter of category 4 lesions was significantly larger than for category 3 lesions and the minimum diameter of category 5 lesions was 
$10 \mathrm{~mm}$ [6]. In contrast, we encountered a diminutive submucosal invasive duodenal adenocarcinoma, 4 mm [14]. Thus, owing to a possibility of carcinoma, a total excisional biopsy by ER for SNADETs may be feasible, even if the SNADETs were small.

Concerning the high risk of complications, there are not many SNADETs for the indication of ESD. Some studies reported that ESD for SNADETs allowed a high rate of en bloc resection and complete resection and a low incidence of lesion recurrence $[3,15,16]$. However, compared to EMR, a high incidence of complications such as intraoperative perforation and delayed perforation after ESD was also reported. Occurrences of intraoperative perforation were reported in $0 \%$ to $3 \%$ and $6.6 \%$ to $31.6 \%$ of cases of duodenal EMR [17-22] and ESD $[16,17,23,24]$, respectively. Occurrences of delayed perforation were reported in $0 \%$ to $2 \%$ and $0 \%$ to $14 \%$ of cases after EMR [17-22] and ESD [17], respectively. Emergency surgery for intraoperative or delayed perforation was reported in $2 \%$ to $14 \%$ of cases [17]. Basically, incidence of complications after ER for SNADETs was significantly higher than that in any other part of the digestive tract $[15,25,26]$. This is due to the anatomical features, which include the following: a narrow lumen; a precipitous flexure that causes poor stability of the endoscope; Brunner's glands in the submucosal layer that stiffen the duodenal wall, resulting in poor mucosal lifting; a thin muscle layer that results in a higher incidence of intraoperative perforation and increased risk of other complications such as postoperative bleeding and delayed perforation; and difficult access if emergency surgery becomes necessary [2, 9, 27]. Risk of intraoperative and delayed perforation was reported not based on location of SNADETs but on the tumor size [23]. It was reported that no intraoperative and delayed perforations occurred in 31 resections of lesions $<30 \mathrm{~mm}$, compared with two perforations ( 1 case, intraoperative perforation; 1 case, delayed perforation) in 19 lesions $\geq 30 \mathrm{~mm}$ [19]. In our study, the three cases had intraoperative perforation in ER, but no significant difference was observed between the size of the intraoperative perforation case and non-intraoperative perforation (intraoperative perforation, $13.3 \pm 6.1 \mathrm{~mm}$; non-intraoperative perforation, $10.7 \pm$ $7.2 \mathrm{~mm}, P=0.30)$. In contrast, the four cases of delayed perforation after ER had significantly larger lesions than the cases of non-delayed perforation (delayed perforation, $22.5 \pm$ $6.5 \mathrm{~mm}$; non-delayed perforation, $10.4 \pm 7.0 \mathrm{~mm}, P=0.0038$ ). Three of four delayed perforation cases occurred after the ER for postoperative bleeding. The cause of delayed perforation was due to repeated endoscopic hemostasis and damaged duodenal muscularis layer. To prevent delayed perforation, some studies reported that prophylactic clipping and nasobiliary/nasopancreatic drainage tube were effective because they protect the mucosal defect against exposure to pancreatic juice and bile $[2,17,25,28]$. Prophylactic clipping was performed in all cases after the fourh case of delayed perforation in October 2010; after that, no cases had delayed perforation. In this study, there were seven lesions that were not closed by clips. Of them, two delayed perforations occurred (29\%). Compared to 164 lesions that were closed by clips, the rate of delayed perforation was significantly higher in the lesions without endoscopic closure by clipping $(2 / 164,1 \% . P<0.05)$. Postoperative bleeding after duodenal EMR was reported in $0 \%$ to $33 \%[2,8$, 18 ] and $0 \%$ to $14.3 \%$ of cases after $\operatorname{ESD}[16,17,23,24]$. It was reported that a statistically significant association was found between bleeding and size of SNEDETs [29]. In our study, postoperative bleeding occurred in five cases. The cases of postoperative bleeding after EMR were significantly larger than the cases of non-postoperative bleeding (postoperative bleeding, $31.0 \pm 2.8 \mathrm{~mm}$; non-postoperative bleeding, $10.1 \pm 10.1 \mathrm{~mm}$, $P=0.0004$ ). To prevent postoperative bleeding, prophylactic $A P C$, clipping of ulcer after ER, and EGD on the day after ER were reported to be effective $[16,17,29]$.

Local recurrence after EMR was reported in $0 \%$ to $37 \%$ of cases $[15-20,23]$. In some retrospective studies, local recurrence after EMR tended to occur in patients with large SNADETs (tumor diameter $>2 \mathrm{~cm}$ ) or when piecemeal EMR was performed, but most local recurrent lesions could be retreated endoscopically [3, 16, 20-22]. In our study, there were two local recurrences after ER, and both recurrent lesions could be resected by EMR. In contrast, no recurrence and highly en bloc resection rates with ESD have not been reported $[3,6,16,23,24$, 27]. Those results were considered due to the difference in en bloc resection rate between EMR and ESD. The finding of good prognosis of SNADETs resected by ER was due to the high rate of en bloc resection. Therefore, in terms of the low recurrence rate of SNADETs after ER in addition to the high risk of complication of ESD for SNADETs, the indication of ESD for SNADETs would be limited. We cannot make a recommendation about type of ER because of the small number of ESD. Lesions $>25 \mathrm{~mm}$ may be adapted to ESD with the aim of en bloc resection, but risk of complications must be considered. This study included a large number of patients; however, it does have some limitations. It was a retrospective, single-center study, the number of ESD cases was much smaller than for EMR, and some patients were lost to follow-up at other institutions (follow-up rate: $96 \%$ ).

\section{Conclusion}

In conclusion, our data support the clinical validity of ER for SNADETs. To prevent delayed perforation after ER, endoscopic closure of ulcer after ER by clipping may be effective.

\section{Competing interests}

None

References

[1] Tsuji S, Doyama H, Tsuji K et al. Preoperative endoscopic diagnosis of superficial non-ampullary duodenal epithelial tumors, including magnifying endoscopy. World J Gastroenterol 2015; 21: 11832 11841

[2] Seo JY, Hong SJ, Han JP et al. Usefulness and safety of endoscopic treatment for nonampullary duodenal adenoma and adenocarcinoma. J Gastroenterol Hepatol 2014; 29: $1692-1698$ 
[3] Kakushima N, Ono H, Takao T et al. Method and timing of resection of superficial non-ampullary duodenal epithelial tumors. Dig Endosc 2014; $26: 35-40$

[4] Jepsen JM, Persson M, Jakobsen NO et al. Prospective study of prevalence and endoscopic and histopathologic characteristics of duodenal polyps in patients submitted to upper endoscopy. Scand J Gastroenterol 1994; 29: $483-487$

[5] Schottenfeld D, Beebe-Dimmer JL, Vigneau FD. The epidemiology and pathogenesis of neoplasia in the small intestine. Ann Epidemiol 2009; 19: $58-69$

[6] Goda K, Kikuchi D, Yamamoto Y et al. Endoscopic diagnosis of superficial non-ampullary duodenal epithelial tumors in Japan: multicenter case series. Dig Endosc 2014; 26: 23 - 29

[7] Pittayanon R, Imraporn B, Rerknimitr R et al. Advances in diagnostic endoscopy for duodenal, including ampullary, adenoma. Dig Endosc 2014; $26: 10-15$

[8] Friedland S. Endoscopic resection of duodenal adenomas: endoscopic mucosal resection or endoscopic submucosal dissection? Endoscopy 2015; 47: $99-100$

[9] Oka S, Tanaka S, Nagata S et al. Clinicopathologic features and endoscopic resection of early primary nonampullary duodenal carcinoma. J Clin Gastroenterol 2003; 37: 381-386

[10] Stolte M. The new Vienna classification of epithelial neoplasia of the gastrointestinal tract: advantages and disadvantages. Virchows Arch 2003; 442: 99-106

[11] Yoshimura N, Goda K, Tajiri H et al. Endoscopic features of nonampullary duodenal tumors with narrow-band imaging. Hepatogastroenterology 2010; 57: 462-467

[12] Mizumoto T, Sanomura Y, Tanaka $S$ et al. Clinical usefulness of magnifying endoscopy for non-ampullary duodenal tumors. Endosc Int Open 2017; 5: 297 - 302

[13] Ryan DP, Schapiro RH, Warshaw AL. Villous tumors of the duodenum. Ann Surg 1986; 203: $301-306$

[14] Yorita N, Sanomura Y, Tanaka S. A case of diminutive duodenal deep submucosal invasive adenocarcinoma resected by endoscopic mucosal resection. Dig Endosc 2018; 2: 264

[15] Kakushima N, Kanemoto H, Tanaka M et al. Treatment for superficial non-ampullary duodenal epithelial tumors. World J Gastroenterol 2014; 20: $12501-12508$
[16] Yamamoto Y, Yoshizawa N, Tomida H et al. Therapeutic outcomes of endoscopic resection for superficial non-ampullary duodenal tumor. Dig Endosc 2014; 26: 50 - 56

[17] Nonaka S, Oda I, Tada K et al. Clinical outcome of endoscopic resection for nonampullary duodenal tumors. Endoscopy 2015; 47: 129 135

[18] Lépilliez V, Chemaly M, Ponchon T. Endoscopic resection of sporadic duodenal adenomas: an efficient technique with a substantial risk of delayed bleeding. Endoscopy 2008; 40: 806-810

[19] Fanning SB, Bourke MJ, Williams S] et al. Giant laterally spreading tumors of the duodenum: endoscopic resection outcomes, limitations, and caveats. Gastrointest Endosc 2012; 75: 805-812

[20] Apel D, Jakobs R, Spiethoff A et al. Follow-up after endoscopic snare resection of duodenal adenomas. Endoscopy 2005; 37: 444-448

[21] Alexander S 1, Bourke MJ, Williams S] et al. EMR of large, sessile, sporadic nonampullary duodenal adenomas: technical aspects and long-term outcome (with videos). Gastrointest Endosc 2009; 69: $66-73$

[22] Abbass R, Rigaux J, Al-Kawas FH. Nonampullary duodenal polyps: characteristics and endoscopic management. Gastrointest Endosc 2010; 71: 754-759

[23] Jung JH, Choi KD, Ahn JY et al. Endoscopic submucosal dissection for sessile, nonampullary duodenal adenomas. Endoscopy 2013; 45: $133-135$

[24] Matsumoto S, Miyatani H, Yoshida Y. Endoscopic submucosal dissection for duodenal tumors: a single-center experience. Endoscopy 2013; 45: $136-137$

[25] Inoue T, Uedo N, Yamashina T et al. Delayed perforation: a hazardous complication of endoscopic resection for non-ampullary duodenal neoplasm. Dig Endosc 2014; 26: 220-227

[26] Ono H, Kaise M, Nonaka S et al. Clinical issues of duodenal EMR/ESD. Stom Intest (in Japanese with English abstract) 2011; 46: 1669-1677

[27] Honda T, Yamamoto H, Sugano K. Endoscopic submucosal dissection for superficial duodenal neoplasms. Dig Endosc 2009; 21: 270-274

[28] Takahashi T, Ando T, Kabeshima Y et al. Borderline cases between benignancy and malignancy of the duodenum diagnosed successfully by endoscopic submucosal dissection. Scand J Gastroenterol 2009; 44: $1377-1383$

[29] Aschmoneit-Messer I, Richl J, Pohl J et al. Prospective study of acute complication rates and associated risk factors in endoscopic therapy for duodenal adenomas. Surg Endosc 2015; 29: 1823 -1830 